\section{Gold in the News - A look at recent stories concerning gold}

For more news stories related to gold please see the newsfeed at www.utiliseGold.com which is updated regularly.

\section{Gold demand hits record value}

Dollar demand for gold reached an all time quarterly record of US\$32bn in the third quarter of 2008 as investors around the world sought refuge from the global financial meltdown, and jewellery buyers returned to the market in droves on a lower gold price. This figure was $45 \%$ higher than the previous record in Q2 2008.Tonnage demand was also 18\% higher than a year earlier. Industrial and dental demand declined to 104 tonnes during the quarter $11 \%$ down on year-earlier levels. Electronics, the largest component of industrial demand, was hampered by the downturn in the global economy and a lack of confidence within world markets.

For further information see www.gold.org

\section{Gold atom weighed}

Researchers have developed new technology that can measure the mass of a single atom of gold, it has been claimed. Scientists from Berkeley Lab and the University of California (UC) have created a nanoelectromechanical system (NEMS) for this purpose according to Nanotechnology Today. They discovered that a gold atom has a mass of $3.25 \times 10^{-25}$ kilograms. Alex Zettl, who led the study, holds joint positions at Berkeley Lab's material sciences division and UC's physics department.

\section{Gold-vanadium oxide for RF devices}

According to website www.ibridgenetwork.org, Lehigh University have developed a new gold-vanadium oxide alloy that exhibits high hardness and low electrical resistivity compared to other gold alloys used in micromechanical switches used in communication and sensing (e.g., radar) equipment. One design for such a switch depends on the reliable closure of electrical contacts for billions of cycles. Gold is the most common material for these contacts, but suffers from reliability problems due to inherent softness.

Several gold alloys such as gold-platinum have been proposed as replacements, but some electrical performance is lost in exchange for increasing lifetime. Initial experiments with the new Au-vanadium oxide nanoparticle-strengthened alloys indicate the potential for greatly increased lifetime with less sacrifice of electrical performance. Furthermore, the material cost should be less than for a pure gold or gold-platinum alloy electrode. Vanadium is an acceptable material in many semiconductor fabrication facilities and may therefore enable easy adoption.

Lehigh University are seeking licensing agreements, further research sponsorship and product development partnerships centred around the technology.

\section{New European record efficiency for solar cells using gold wires}

By achieving 39.7\% efficiency for a multi-junction solar cell, researchers at the Fraunhofer Institute for Solar Energy Systems ISE in Freiburg have exceeded their own European record of $37.6 \%$ which they achieved just a short time ago. III-V semiconductor multi-junction solar cells are used in photovoltaic concentrator technology for solar power stations.

In the newly developed cell, the solar generated current is conducted through a network of thin wires (see below) from the middle of the solar cell to the edge, where it is then picked up by a $50 \mu \mathrm{m}$ gold wire. Particularly under concentrated sunlight, the structure of this metal network is decisive. The metal wires must be big enough to transport, with low resistance, the large currents which are generated under concentrated sunlight. At the same time the wires must be as small as possible since the sunlight cannot penetrate through metal and thus the cell area covered by metal cannot be used for the electrical conversion.

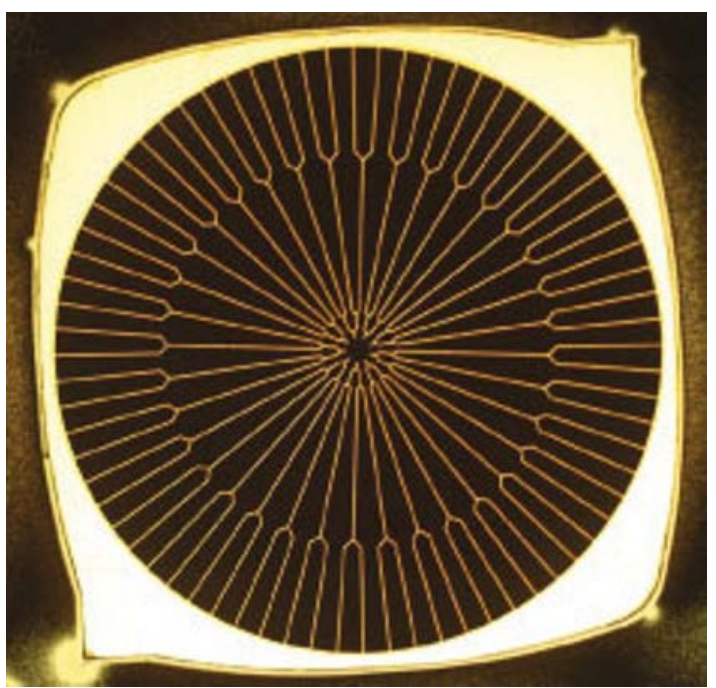

For more information go to:

http://www.ise.fhg.de/press-and-media/press-releases/pressreleases-2008/39.7-2013-new-european-record-efficiencyfor-solar-cells-achieved-by-fraunhofer-ise 